\title{
Monitoring Value of Serum HER2 as a Predictive Biomarker in Patients with Metastatic Breast Cancer
}

This article was published in the following Dove Press journal:

Cancer Management and Research

\section{Pengyu Zhang $\mathbb{D}^{1}{ }^{1, *}$ Jun Xiao (iD) ${ }^{2, *}$ Yingxin Ruan ${ }^{3} *$ Zhenzhen Zhang' Xuejun Zhang (iD ${ }^{2}$ \\ 'Department of Blood Transfusion, Tianjin Medical University Cancer Institute and Hospital, National Clinical Research Center of Cancer, Key Laboratory of Cancer Prevention and Therapy, Key Laboratory of Breast Cancer Prevention and Therapy, Tianjin Medical University, Ministry of Education, Tianjin 300060, People's Republic of China; ${ }^{2}$ Department of Immunology, Key Laboratory of Educational Ministry of China, Tianjin Key Laboratory of Cellular and Molecular Immunology, School of Basic Medical Sciences, Tianjin Medical University, Tianjin 300070, People's Republic of China; ${ }^{3}$ Department of Nephrology, General Hospital of Tianjin Medical University, Tianjin 300052, People's Republic of China}

*These authors contributed equally to this work
Correspondence: Xuejun Zhang Department of Immunology, Key Laboratory of Educational Ministry of China, Tianjin Key Laboratory of Cellular and Molecular Immunology, School of Basic Medical Sciences, Tianjin Medical University, No. 22 Qixiangtai Road, Heping District, Tianjin 300070, People's Republic of China

Tel +86 I5I 22800672

Email xjzhimmunology@I63.com
Purpose: The aim of this study was to investigate the monitoring value of serum HER2 in patients with metastatic breast cancer.

Patients and Methods: We firstly evaluated the association of serum HER2 levels with tissue HER2 expression and imaging results in 420 breast cancer patients admitted into Tianjin Medical University Cancer Institute and Hospital between April 2016 and December 2018. Secondly, we analyzed serum HER2 levels in breast cancer patients with different metastatic degrees.

Results: There is a higher correlation between serum HER2 and tissue HER2 in breast cancer patients with stage III $(\kappa=0.670, p<0.001)$ and stage IV $(\kappa=0.464, p<0.001)$. Serum HER2 levels were significantly associated with imaging results $(\kappa=0.478, p<0.001)$. The ROC curve analysis showed that serum HER2 was superior to other serum markers for predicting metastatic breast cancer. Multinomial logistic regression revealed that the patients with higher serum HER2 levels would be more likely to have breast cancer metastasis.

Conclusion: Serum HER2 levels in breast cancer patients can partly reflect tissue HER2 expression and tumor imaging changes, and serum HER2 may be used as a biomarker for evaluating metastatic status in patients with breast cancer.

Keywords: serum HER2, breast cancer, tumor metastasis, biomarker

\section{Introduction}

Breast cancer is one of the most common malignant tumors and the second leading cause of cancer death among women. ${ }^{1,2}$ Cases in China account for about $12.2 \%$ of all newly diagnosed breast cancers and $9.6 \%$ of all deaths from breast cancer worldwide. ${ }^{3}$ Based on the status of molecular markers of estrogen receptor (ER), progesterone receptor (PR), and human epidermal growth factor 2 (HER2) in cancer cells, breast cancer can be categorized as three major subtypes: ER and PR positive/ HER2 negative (70\%), HER2 positive (15-20\%), and triple-negative breast cancer $(15 \%)$.

HER2 is a crucial oncogene and a tumor therapy target for HER2-positive patients, HER2 gene amplification and/or protein overexpression occurs in approximately $20 \%$ $30 \%$ of patients with primary breast cancer. ${ }^{4-6}$ Currently, HER2/Neu status is mainly evaluated using immunohistochemistry (IHC) and fluorescent in situ hybridization (FISH) in the clinical setting. ${ }^{7}$ However, both assays have been shown to have some limitations, such as invasive assays for patients, lack of "real-time" follow-up and dependency of both assays on tumor biopsy or surgery. ${ }^{8}$ Therefore, they are not suitable for monitoring disease progression in breast cancer patients. 
In addition to histopathology testing, imaging methods are routinely used as early diagnosis and monitoring response to therapy, but they also have limitations such as radiation risk and inability to differentiate small lesions. ${ }^{4,9}$ In recent years, many researchers have been searching for sensitive and specific indicators that reflect the status of breast cancer, in order to provide a valuable reference for the diagnosis, treatment, and prognosis of breast cancer patients. ${ }^{10}$

Compared with histopathology and imaging methods, serum markers are easier to detect and "real-time" followup. The HER2 extracellular domain (ECD) on the surface of HER2-positive breast cancer cells can fall off and enter the circulation, which is the basis for the serological detection of HER2. ${ }^{8,11}$ In fact, the US Food and Drug Administration approved the first enzyme-linked immunosorbent assay for monitoring HER2 ECD in 2000. Although serum HER2 testing has not been used in clinical practice in the past decade, ${ }^{10}$ some studies suggested that serum HER2 ECD might be a promising biomarker for monitoring metastasis and recurrence. ${ }^{12,13}$

In this study, we collected the data of breast cancer patients treated at Tianjin Medical University Cancer Institute and Hospital to investigate possible monitoring value of serum HER2 in clinical utility, especially predictive value of serum HER2 in metastatic breast cancer.

\section{Patients and Methods}

\section{Patients and Eligibility Criteria}

The clinical data, including age, serology results, imaging results (X-ray, ultrasound, MRI), pathology results, were collected from 420 female breast cancer patients admitted into Tianjin Medical University Cancer Institute and Hospital between April 2016 and December 2018. All breast cancer cases were confirmed by imaging or pathology diagnoses. All subjects excluded autoimmune diseases, cardiovascular diseases, severe liver and kidney diseases, blood diseases, infectious diseases, and other malignant tumors. Tumor node metastasis (TNM) staging was based on the criteria of the American Joint Committee on Cancer (AJCC) Cancer Staging Manual. ${ }^{14}$

\section{Serum Sample Processing}

We collected $3 \mathrm{~mL}$ of fasting venous blood from each patient into a coagulation tube in the morning of the second day after hospitalization. Serum was obtained by centrifuged at $1200 \mathrm{~g}$ for 5 mins at $4^{\circ} \mathrm{C}$ for subsequent experiments or stored in aliquots at $-80^{\circ} \mathrm{C}$ until assay. Samples with hemolysis, lipemia, or other ineligibilities were excluded.

\section{Serum Markers Detection}

Serum HER2 level in breast cancer patients was measured with the ADVIA Centaur XP automated chemiluminescence immunoassay analyzer (Siemens, Germany). The company provided the reagents, calibrators, and control serums for analysis. Serum HER2 concentration exceeding $15.2 \mathrm{ng} / \mathrm{mL}$ is considered positive, as recommended for breast cancer by Siemens. According to the change of serum HER2 levels, the patients were classified as 3 groups: "Unchanged", "Increased" and "Decreased". The criteria are based on "the Chinses Society Guideline recommendations for Clinical application of tumor markers" (Chin J Lab Med, 2012;35(2):103-116). "Unchanged" is defined as within $25 \%$ changes for serum HER 2 before and after treatment; "Increased": at least $25 \%$ increase than before treatment; "Decreased": at least 25\% decrease than before treatment. Serum HER2 ECD measurement was carried out in a blinded manner without knowledge about the results of HER2 IHC and FISH. Samples were also tested for concentrations of CEA, CA15-3, and CA125 using the automated electrochemical luminescence immunoassay system (Roche, Germany) in accordance with the manufacturer's instructions. Control serum (Tumor Marker Plus, Lot 54640) was purchased from Bio-Rad (Bio-Rad, USA).

\section{Tissue Expression of HER2: IHC and FISH}

Tumor biopsies of primary lesion were fixed in $10 \%$ neutralbuffered formalin overnight and embedded in paraffin blocks. Paraffin-embedded tissues were cut into 4- $\mu \mathrm{m}$ thick slices, and IHC for HER2 was performed with BenchMark XT Automated IHC/ISH slide staining system (VENTANA) using anti-HER2/neu antibody (clone number 4B5, VENTANA). Each case was scored independently according to the 2018 ASCO/CAP Guidelines by two pathologists. IHC for estrogen receptor (ER) was performed using monoclonal rabbit anti-human estrogen receptor antibody (clone EP1, Roche) and evaluated by two pathologists independently according to the ASCO/CAP guidelines. IHC for progesterone receptor (PR) was performed using monoclonal mouse anti-human progesterone receptor antibody (clone \# 16, Leica) and evaluated by two pathologists independently recording the proportion of positive tumor cells. ${ }^{15}$ Furthermore, Fluorescence in situ hybridization (FISH) was performed with Vysis PathVysion probe set (Abbott Diagnostics), according to the protocol recommended by 
the manufacturer if HER2 protein expression in IHC $2+$ cases. Tumor specimens with a HER2:CEP17 signal ratio $\geq 2.0$ were considered HER2 FISH positive. ${ }^{15}$

\section{Tumor Response Evaluation}

The criteria of tumor response evaluation have been adapted from "New Guidelines to Evaluate the Response to Treatment in Solid Tumors", the patients were divided into three groups: "Unchanged" means neither sufficient shrinkage $(30 \%)$ to qualify for partial response nor sufficient increase $(20 \%)$ to qualify for progressive disease, taking as reference the smallest sum longest diameter since the treatment started; "Aggravation" -at least a $20 \%$ increase since treatment started, and "Remission" at least a $30 \%$ decrease since treatment started.

\section{Statistical Methods}

Serum tumor markers (HER2, CA15-3, CEA and CA125) in our study were non-normally distributed data and analyzed by the median and quartile interval. We performed Weighted kappa index analysis to determine the correlation of "serum HER2" with "tissue HER2" and "imaging results" in breast cancer patients. Multinomial logistic regression analysis was conducted to evaluate the serum HER2 as a metastasis-predictive biomarker in patients with breast cancer. The diagnostic performance of each serum marker for predicting metastasis was evaluated by receiver operating characteristic (ROC) curve. The enumeration data were expressed as number (percentage) and were compared with the $\chi^{2}$ test. For the measurement data, we first performed the test of normality, then the differences among groups were compared via the MannWhitney $U$-test (nonparametric test). Data analyses were performed by SPSS 22.0 for Windows (SPSS Inc, USA). All Figures were plotted and analyzed with GraphPad Prism v8 for Windows (GraphPad Software, USA).

\section{Results}

\section{Clinical Characteristics of Breast Cancer Patients}

A total of 420 female breast cancer patients were enrolled in this study, including 148 patients with non-metastasis and 270 patients with metastasis. Table 1 shows the essential clinical information of enrolled patients, including the case number in

Table I Basic Information and Clinical Characteristics of the Study Populations

\begin{tabular}{|c|c|c|c|c|}
\hline & $\begin{array}{l}\text { Non-Metastasis } \\
\text { Group }\end{array}$ & $\begin{array}{l}\text { Local Metastasis } \\
\text { Group }\end{array}$ & $\begin{array}{l}\text { Distance Metastasis } \\
\text { Group }\end{array}$ & Total \\
\hline $\begin{array}{l}\text { Number } \\
\text { Age (Mean } \pm \text { SD) }\end{array}$ & $\begin{array}{l}149 \\
52.78 \pm 10.94\end{array}$ & $\begin{array}{l}123 \\
52.88 \pm 10.79\end{array}$ & $\begin{array}{l}148 \\
51.65 \pm \mid 1.25\end{array}$ & $\begin{array}{l}420 \\
-\end{array}$ \\
\hline $\begin{array}{c}\text { Tumor classification } \\
\text { Ductal carcinoma } \\
\text { Lobular carcinoma }\end{array}$ & $\begin{array}{l}122 \\
27\end{array}$ & $\begin{array}{l}99 \\
24\end{array}$ & $\begin{array}{l}121 \\
27\end{array}$ & $\begin{array}{l}342 \\
78\end{array}$ \\
\hline $\begin{array}{l}\text { TNM category } \\
\text { I } \\
\text { II } \\
\text { III } \\
\text { IV }\end{array}$ & $\begin{array}{l}80 \\
53 \\
16 \\
0\end{array}$ & $\begin{array}{l}0 \\
50 \\
58 \\
15\end{array}$ & $\begin{array}{l}0 \\
7 \\
5 \\
136\end{array}$ & $\begin{array}{l}80 \\
110 \\
79 \\
151\end{array}$ \\
\hline $\begin{array}{l}\text { Tissue HER2 } \\
+ \\
+\end{array}$ & $\begin{array}{l}101 \\
48\end{array}$ & $\begin{array}{l}80 \\
43\end{array}$ & $\begin{array}{l}90 \\
58\end{array}$ & $\begin{array}{l}271 \\
149\end{array}$ \\
\hline $\begin{array}{r}\text { ER } \\
+ \\
-\end{array}$ & $\begin{array}{l}87 \\
62\end{array}$ & $\begin{array}{l}73 \\
50\end{array}$ & $\begin{array}{l}74 \\
74\end{array}$ & $\begin{array}{l}234 \\
186\end{array}$ \\
\hline $\begin{array}{r}\text { PR } \\
+ \\
-\end{array}$ & $\begin{array}{l}72 \\
77\end{array}$ & $\begin{array}{l}41 \\
82\end{array}$ & $\begin{array}{l}68 \\
80\end{array}$ & $\begin{array}{l}181 \\
239\end{array}$ \\
\hline
\end{tabular}

Note: Criteria for TNM classification and tissue HER2/ER/PR detection are shown in the section of "Patients and Methods".

Abbreviations: SD, standard deviation; ER, estrogen receptor; PR, progesterone receptor; +, positive; -, negative. 
each group, age, tumor classification, TNM staging, and the statue of HER2, ER, and PR in breast cancer tissue.

\section{Correlation Between Serum HRE2 Level and Tissue HER2 Expression in Patients with Breast Cancer}

We choose the patients with serum HER2 and tissue HER2 test interval of fewer than 3 months, and 213 of the 420 patients met this requirement. Weighted kappa index $(\kappa)$ was calculated to analyze the agreement between serum HER2 level and tissue HER2 expression. The range of $\kappa$ lies between -1 and 1 , which $\kappa$ range from 0.81 to 1.00 indicates very high agreement, 0.61 to 0.80 (high agreement), 0.41 to 0.60 (moderate agreement), 0.21 to 0.40 (low agreement), and $\kappa<0.2$ (fragile agreement). Table 2 shows that the agreement was low in the patients with stage I $\quad(\kappa=-0.202, p=0.140) / \mathrm{II} \quad(\kappa=0.177, p=0.137)$,

Table 2 Correlation Between Serum HER2 Level and Tissue HER2 Expression

\begin{tabular}{|c|c|c|c|c|c|}
\hline \multirow{2}{*}{$\begin{array}{l}\text { TNM } \\
\text { Category }\end{array}$} & \multirow{2}{*}{$\begin{array}{l}\text { Serum } \\
\text { HER2 }\end{array}$} & \multicolumn{2}{|c|}{ Tissue HER2 } & \multirow[t]{2}{*}{$\kappa$} & \multirow[t]{2}{*}{$p$ value } \\
\hline & & $\begin{array}{l}\text { Positive } \\
(+)\end{array}$ & $\begin{array}{l}\text { Negative } \\
(-)\end{array}$ & & \\
\hline I & $\begin{array}{l}+ \\
-\end{array}$ & $\begin{array}{l}0 \\
11\end{array}$ & $\begin{array}{l}3 \\
14\end{array}$ & -0.2 & 0.14 \\
\hline$\|$ & + & $\begin{array}{l}7 \\
13\end{array}$ & $\begin{array}{l}9 \\
40\end{array}$ & 0.177 & 0.137 \\
\hline III & + & $\begin{array}{l}14 \\
2\end{array}$ & $\begin{array}{l}5 \\
23\end{array}$ & 0.67 & $<0.001$ \\
\hline IV & $\begin{array}{l}+ \\
-\end{array}$ & $\begin{array}{l}30 \\
2\end{array}$ & $\begin{array}{l}18 \\
22\end{array}$ & 0.464 & $<0.001$ \\
\hline
\end{tabular}

Note: Criteria for TNM classification and tissue/serum HER2 detection are shown in the section of "Patients and Methods".

Abbreviations: $\kappa$, weighted kappa index; +, positive; -, negative. a high agreement in stage III $(\kappa=0.670, p<0.001)$, and a moderate agreement in stage IV $(\kappa=0.464, p<0.001)$.

\section{Correlation of Serum HRE2 with Imaging Diagnosis in Breast Cancer Patients}

We next analyzed the association between serum HER2 and imaging diagnosis. 237 of the 420 patients with serum HER2 detection and imaging diagnosis interval of fewer than 3 months were included in the analysis. According to tumor response evaluation, the patients were divided into three groups: "Unchanged", "Aggravation" and "Remission". Correspondingly, according to the changes of serum HER2 levels, the patients were divided into three groups: "Unchanged", "Increased" and "Decreased". Weighted kappa index ( $\kappa)$ was calculated to analyze the agreement between serum HER2 level and imaging diagnosis. Our results showed there was a moderate agreement between serum HER 2 and imaging diagnosis, as showed in Table 3 $(\kappa=0.478, p<0.001)$.

\section{Relationship of Serum HER2 Levels with Metastatic Breast Cancer}

To investigate the predictive role of serum HER2 in metastatic breast cancer, we analyzed the levels of serum HER2 and other serum biomarkers, including CEA, CA15-3, and CA125, in the breast cancer patients with different metastasis status. Among 420 patients, two patients without the data of serum markers were excluded from the analysis. Thus, 418 breast cancer patients were enrolled in the analysis, including 270 patients with metastasis (Metastasis group, MG) and 148 patients without metastasis (Non-metastasis group, NMG). Furthermore, MG was subdivided into two groups, including 123 patients with local metastasis (local metastasis group, LMG) and 147 patients with distant metastasis (distant metastasis group, DMG).

Table 3 Correlation of Serum HER2 Level with Imaging Diagnosis

\begin{tabular}{|c|c|c|c|c|c|c|c|}
\hline & & \multicolumn{4}{|c|}{ Imaging Diagnosis $^{b}$} & \multirow[t]{2}{*}{ к } & \multirow[t]{2}{*}{$p$ value } \\
\hline & & Unchanged & Aggravation & Remission & Total & & \\
\hline Serum HER2 ${ }^{\mathrm{a}}$ & $\begin{array}{l}\text { Unchanged } \\
\text { Increased } \\
\text { Decreased } \\
\text { Total }\end{array}$ & $\begin{array}{l}197 \\
25 \\
15 \\
237\end{array}$ & $\begin{array}{l}55 \\
81 \\
4 \\
140\end{array}$ & $\begin{array}{l}11 \\
1 \\
31 \\
43\end{array}$ & $\begin{array}{l}263 \\
107 \\
50 \\
420\end{array}$ & 0.48 & $<0.001$ \\
\hline
\end{tabular}

Notes: "The change of serum HER2 levels within $25 \%$ is defined as "Unchanged"; "Increased": at least $25 \%$ increase before treatment; "Decreased": at least $25 \%$ decrease than before treatment. 'Tumor volume (imaging diagnosis) changes within $20 \%$ are defined as "Unchanged”; "Aggravation": at least a $20 \%$ increase since treatment started; "Remission": at least a $20 \%$ decrease since treatment started.

Abbreviation: $\kappa$, weighted kappa index. 
Table 4 Concentrations of Serum Markers in the Patients with Different Metastatic Status

\begin{tabular}{|l|l|l|l|l|}
\hline & HER2 $(\mathbf{n g} / \mathbf{m L})$ & CAI5-3 $(\mathbf{U} / \mathbf{m L})$ & CEA $(\mu \mathrm{g} / \mathbf{L})$ & CAI25 (U/mL) \\
\hline NMG & $10.48(12.35,14.73)$ & $11.095(7.77,16.83)$ & $1.83(1.10,2.89)$ & $12.42(8.44,16.42)$ \\
MG & $16.85(13.10,26.70)^{\mathrm{a}}$ & $19.17(12.74,52.87)^{\mathrm{a}}$ & $2.90(1.65,6.85)^{\mathrm{a}}$ & $15.85(10.55,33.58)^{\mathrm{a}}$ \\
LMG & $15.00(12.25,17.5)^{\mathrm{d}}$ & $15.57(10.21,21.72)^{\mathrm{d}}$ & $2.32(1.4,4.275)^{\mathrm{e}}$ & $13.2(8.78,19.78)$ \\
DMG & $22.1(15.05,50.6)^{\mathrm{b}, \mathrm{c}}$ & $32.52(15.21,96.12)^{\mathrm{b}, \mathrm{c}}$ & $3.79(2.05,11.33)^{\mathrm{b}, \mathrm{c}}$ & $20.32(11.91,65.99)^{\mathrm{b}, \mathrm{c}}$ \\
\hline
\end{tabular}

Notes: Data were expressed as the median \pm quartile interval. ${ }^{a} \mathrm{p}<0.00 \mathrm{I}, \mathrm{MG}(\mathrm{n}=270)$ compared with NMG $(\mathrm{n}=148), \mathrm{Z}=-8.873,-7.48 \mathrm{I},-5.825$ and -5.013 . ${ }^{\mathrm{b}} \mathrm{p}<0.00 \mathrm{I}$, DMG $(n=147)$ compared with LMG $(n=123), Z=-5.987,-5.949,-4.244$ and $-5.176 .{ }^{c} p<0.001$, DMG $(n=\mid 47)$ compared with NMG ( $\left.n=148\right), Z=-9.805,-8.674,-6.938$ and -6.718 . ${ }^{\mathrm{d}} \mathrm{p}<0.00 \mathrm{I},{ }^{\mathrm{e}} \mathrm{p}<0.01, \mathrm{LMG}(\mathrm{n}=123)$ compared with NMG $(\mathrm{n}=148), \mathrm{Z}=-5.044,-3.865,-2.798$ and -1.558 .

Abbreviations: NMG, non-metastasis group; MG, metastasis group; LMD, local metastasis group; DMG, distant metastasis group.

We firstly analyzed the levels of serum markers expression in the breast cancer groups with different metastatic status. Our results showed that the serum levels of HER2, CEA, CA15-3, and CA125 were significantly higher when compared MG with NMG or compared DMG with LMG $(p<0.001)$. When compared LMG with NMG, we found a significant elevation in the serum levels of HER2, CEA, and CA15-3, but no significant difference for CA125 (Table 4). These data showed that serum HER2 and other serum tumor markers could increase in patients with metastatic breast cancer, especially with distant metastasis. Furthermore, ROC analysis revealed that when compared these serum markers in the groups with different metastasis status, serum HER2 was superior to other serum markers for predicting metastatic breast cancer (Figure 1).

To evaluate the significance of serum HER2 in predicting the metastasis status of breast cancer patients, we further performed multinomial logistic regression analysis.

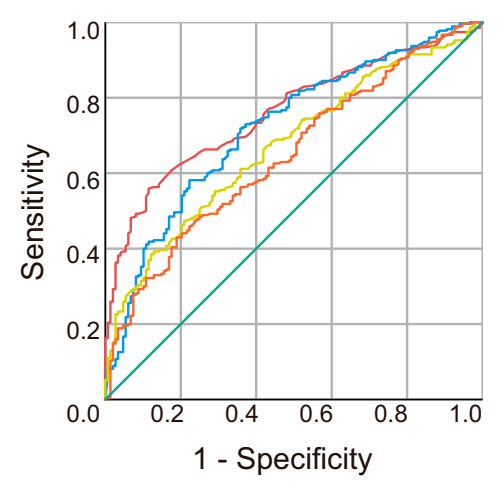

A. MG vs. NMG

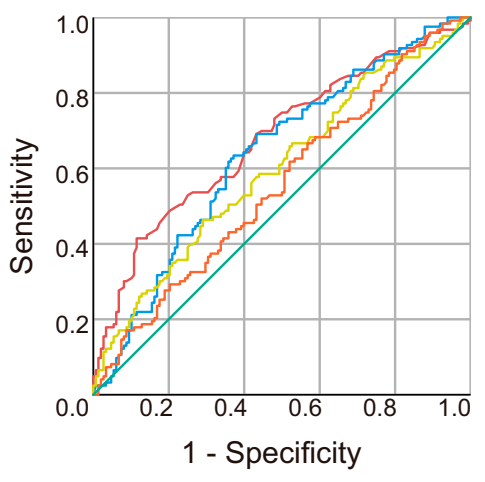

C. LMG vs. NMG

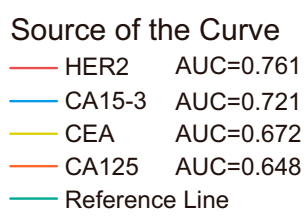

Source of the Curve

- HER2 AUC $=0.678$

- CA15-3 AUC $=0.636$

CEA AUC $=0.599$

CA125 AUC $=0.555$

Reference Line

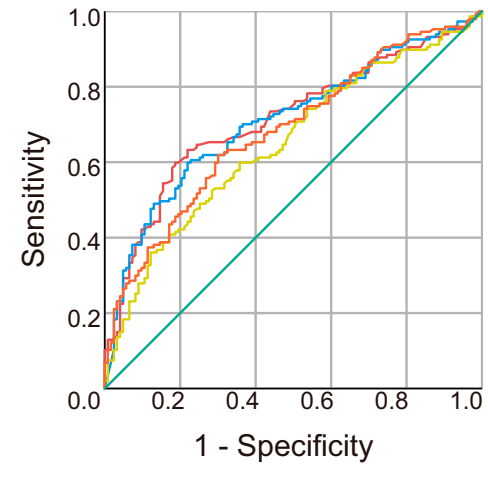

B. DMG vs. LMG

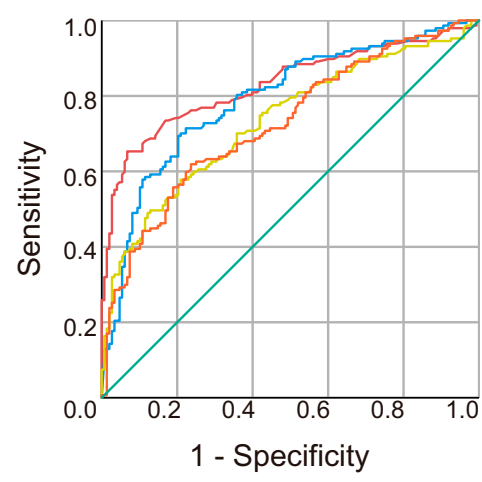

D. DMG vs. NMG
Source of the Curve

— HER2 AUC $=0.714$

- CA15-3 AUC $=0.710$

- CEA AUC $=0.650$

- CA125 AUC $=0.683$

- Reference Line
Source of the Curve

- HER2 AUC $=0.830$

- CA15-3 AUC $=0.792$

- CEA AUC $=0.734$

- CA125 AUC $=0.726$

- Reference Line

Figure I ROC curve comparison of serum HER2 with other markers in the different groups.

Notes: (A) MG ( $n=270)$ vs NMG ( $n=148)$. (B) DMG $(n=147)$ vs LMG $(n=123)$. (C) LMG $(n=123)$ vs NMG $(n=148)$. (D) DMG $(n=147)$ vs NMG $(n=148)$.

Abbreviations: AUC, area under the ROC curve; NMG, non-metastasis group; MG, metastasis group; LMD, local metastasis group; DMG, distant metastasis group. 
Table 5 Multinomial Logistic Regression for Prediction Breast Cancer Metastasis

\begin{tabular}{|c|c|c|c|c|c|c|}
\hline \multirow[t]{2}{*}{ Metastasis Status Group } & \multicolumn{3}{|c|}{ Unadjusted $^{\mathbf{a}}$} & \multicolumn{3}{|c|}{ Adjusted $^{b}$} \\
\hline & OR & $95 \% \mathrm{Cl}$ & $p$ value & OR & $95 \% \mathrm{Cl}$ & $p$ value \\
\hline \multicolumn{7}{|l|}{ NMG (baseline) } \\
\hline \multicolumn{7}{|l|}{ LMG } \\
\hline $\begin{array}{l}\text { sHER2 }(\mathrm{ng} / \mathrm{mL}) \\
\text { Age } \\
\text { CAI5-3 (U/mL) } \\
\text { CEA }(\mu \mathrm{g} / \mathrm{mL}) \\
\text { CAI25 (U/mL) } \\
\text { ER } \\
\quad- \\
\quad+ \\
\text { PR } \\
\quad- \\
+ \\
\text { Tissue HER2 } \\
\quad- \\
+\end{array}$ & 1.148 & $(1.090-1.210)$ & 0.000 & $\begin{array}{l}1.131 \\
1.001 \\
0.999 \\
1.012 \\
0.994 \\
\text { Ref. } \\
1.331 \\
\text { Ref. } \\
0.459 \\
\text { Ref. } \\
\text { I.058 }\end{array}$ & $\begin{array}{l}(1.068-1.198) \\
(0.979-1.024) \\
(0.992-1.007) \\
(0.978-1.046) \\
(0.987-1.000) \\
(0.663-2.673) \\
(0.228-0.927) \\
(0.626-1.790)\end{array}$ & $\begin{array}{l}0.000 \\
0.909 \\
0.699 \\
0.498 \\
0.064 \\
0.421 \\
0.030 \\
0.833\end{array}$ \\
\hline DMG & & & & & & \\
\hline $\begin{array}{l}\text { sHER2 }(\mathrm{ng} / \mathrm{mL}) \\
\text { Age } \\
\text { CAI5-3 }(\mathrm{U} / \mathrm{mL}) \\
\text { CEA }(\mu \mathrm{g} / \mathrm{mL}) \\
\text { CAI25 }(\mathrm{U} / \mathrm{mL}) \\
\text { ER } \\
\quad- \\
\quad+ \\
\text { PR } \\
\quad- \\
+ \\
\text { Tissue HER2 IHC } \\
\quad- \\
+\end{array}$ & 1.167 & $(1.107-1.229)$ & 0.000 & $\begin{array}{l}1.142 \\
1.002 \\
1.006 \\
1.012 \\
0.999 \\
\text { Ref. } \\
0.926 \\
\text { Ref. } \\
0.964 \\
\text { Ref. } \\
\text { I.520 }\end{array}$ & $\begin{array}{l}(1.079-1.209) \\
(0.978-1.026) \\
(1.000-1.013) \\
(0.979-1.046) \\
(0.996-1.003) \\
(0.434-1.977) \\
(0.459-2.025) \\
(0.860-2.689)\end{array}$ & $\begin{array}{l}\mathbf{0 . 0 0 0} \\
0.875 \\
0.066 \\
0.491 \\
0.670 \\
\\
0.842 \\
0.922 \\
0.150\end{array}$ \\
\hline
\end{tabular}

Notes: An OR >I indicates an increased likelihood for breast cancer metastasis. Bold values represent statistical significance $(p<0.05)$. NMG is selected as baseline. ${ }^{a}$ Multinomial logistic regression model including serum HER2 level. '⿳亠口冋口十 and tissue HER2.

Abbreviations: OR, odds ratio; $95 \% \mathrm{Cl}$, confidence interval; ER, estrogen receptor; PR, progesterone receptor; +, positive; -, negative; n.s, not significant; Ref., reference factor.

Table 5 shows generally consistent findings in both unadjusted and adjusted models. Unadjusted analysis showed a significant association of serum HER2 levels with metastasis status ( $p=0.000)$. After adjustment for age, CA15-3, CEA, CA125, ER, PR, and tissue HER2, the associations between serum HER2 and breast cancer metastasis status remained significant $(p=0.000)$. Taken together, our results showed that the breast cancer patients with higher serum HER2 levels were more likely to have breast cancer metastasis.

\section{Discussion}

HER2 is a $185 \mathrm{KDa}$ transmembrane glycoprotein with tyrosine kinase activity encoded by proto-oncogene HER2/neu (c-erbB-2) located on chromosome 17q1221.32. ${ }^{16,17}$ HER2 has three domains, including an extracellular domain (ECD, ligand binding), a transmembrane domain (signal transduction), and an intracellular domain (kinase activity). ${ }^{8,18}$ HER2 overexpression has been reported in 20\%-25\% of all breast cancers and is associated with poor prognosis and decreased overall patient 
survival. ${ }^{19}$ Therefore, evaluating HER2 status is critical for breast cancer prognosis, treatment options, and predicting clinical response to HER2-targeted therapy. ${ }^{4,20}$ So far, IHC and FISH are the most widely used methods in clinical practice to evaluate HER2 status. ${ }^{17}$ However, tissue HER2 detection had its limitations, such as the lack of "real time" follow-up due to the dependency on tumor biopsies ${ }^{13}$ and loss of tissue antigenicity due to improper storage. ${ }^{21,22}$ In contrast, measuring serum HER2 levels is more accessible than collecting tissue specimens for assessing HER2 status. Serum HER2 detection can be repeated during treatment, making it more suitable for monitoring the patient's response to targeted therapy. For late-stage patients, it may be difficult to perform biopsy due to the patients' unwillingness and complicated tumor structure. Based on these reasons, monitoring serum HER2 may be a good alternative for supplement existing HER2 testing.

There is controversy about the correlation between serum HER2 and tissue HER2, some studies showed serum HER2 levels are closely related to tissue HER2 status while other studies argued against the correlation. ${ }^{21,23,24}$ In this study, we found a low concordance of serum HER2 with tissue HER2 in the breast cancer patients with stage I and II, a high concordance in stage III and IV. Mechanistically, we surmise that for breast cancer patients with stage I or II, tumor tissue is localized and there are very little HER2 proteins entering body fluid, resulting in a lower level of HER2 ECD in the patients' body fluids and a discordance of tissue HER2 with serum HER2. With tumor growth, infiltration of surrounding tissues, and local or distant lymphatic metastasis, HER2 ECD levels gradually increase in the patients' body fluids, leading to an abnormal elevation of serum HER2 in the stage III and IV patients and a high concordance between serum HER2 and tissue HER2. Given a high concordance between serum HER2 and tissue HER2 in breast cancer patients with clinical stages III and IV, serum HER2 may be monitored as a biomarker for HER2-targeted therapy in such patients.

In addition, it is possible that some breast cancer patients initially classified as HER2-negative may elevate serum HER2 levels during tumor metastasis. ${ }^{25}$ Although these patients did not receive anti-HER2 targeted therapy, clinical evidence indicated that such patients can benefit from trastuzumab treatment. Underlying mechanisms might involve in the heterogeneity of tumor cells. Initially, there are fewer HER-2 positive tumor cells in the tested tissues from early-stage breast cancer patients, however with constant proliferation of HER2-positive tumor cells with drug resistance and more shedding of HER2 ECDs into the circulation during metastasis, serum HER2 levels may be elevated in the patients with HER2 metastatic cancer. ${ }^{26,27}$

Imaging techniques are important methods for clinical diagnosis and treatment monitoring. ${ }^{28}$ As far as we know, few studies have investigated the correlation between imaging diagnosis and tumor markers. Our data showed a moderate concordance between serum HER2 levels and imaging results $(\kappa=0.48, p<0.001)$, indicating that the change of serum HER2 levels may be closely associated with disease progression. ${ }^{14,22}$

Our results also showed that the breast cancer patients with higher serum HER2 levels were more likely to have breast cancer metastasis. For patients with suspected metastatic or recurrent breast cancer, biopsy should be performed for further confirmation. However, considering some patients' reluctance for biopsy, monitoring serum HER2 levels may be an alternative for predicting metastasis of breast cancer.

It should be noted that monitoring of HER2 ECD will not replace FISH/IHC assays but supplement the tissue assay to offer a real-time monitor of HER2 status in patients. Furthermore, a large-scale analysis is needed to determine whether the level of serum HER 2 can be used to monitor the metastasis of breast cancer.

\section{Conclusion}

In conclusion, this study suggests that there is a high agreement between serum HER2 and tissue HER2 in breast cancer patients in stages III/IV, and serum HER2 levels were significantly associated with imaging results. Breast cancer patients with higher serum HER2 levels were more likely to have breast cancer metastasis. We propose that serum HER2 might be used as an indicator for helping clinicians to evaluate disease progression of breast cancer.

\section{Data Sharing Statement}

The datasets in the study are available from the corresponding author on reasonable request.

\section{Ethics Approval and Informed Consent}

All procedures performed in studies involving human participants were in accordance with the ethical standards of the institutional and/or national research committee and with the 1964 Helsinki declaration and its later amendments or comparable ethical standards. This study was approved by The 
Ethics Committee of Tianjin Medical University Cancer Institute and Hospital, Tianjin, China. Informed consent was obtained from all individual participants included in the study.

\section{Acknowledgments}

We would like to thank the researchers and study participants for their contributions.

\section{Funding}

This study was funded by the Research Project of Tianjin Medical University (No. 2014KYM04), the Natural Science Foundation of Tianjin (No.13JCZDJC30000; 18JCZDJC98300), and the National Natural Science Foundation of China (No. 31240036; 31370891).

\section{Disclosure}

The authors report no conflicts of interest in this work.

\section{References}

1. DeSantis CE, Ma J, Gaudet MM, et al. Breast cancer statistics, 2019. CA Cancer J Clin. 2019;69(6):438-451. doi:10.3322/caac.21583

2. Anastasiadi Z, Lianos GD, Ignatiadou E, Harissis HV, Mitsis M. Breast cancer in young women: an overview. Updates Surg. 2017;69(3):313-317. doi:10.1007/s13304-017-0424-1

3. Fan L, Strasser-Weippl K, Li JJ, et al. Breast cancer in China. Lancet Oncol. 2014;15(7):e279-e289. doi:10.1016/S1470-2045(13)70567-9

4. Waks AG, Winer EP. Breast cancer treatment: a review. JAMA. 2019;321(3):288-300. doi:10.1001/jama.2018.19323

5. von Minckwitz G, Procter M, de Azambuja E, et al. Adjuvant pertuzumab and trastuzumab in early HER2-positive breast cancer. N Engl J Med. 2017;377(2):122-131. doi:10.1056/NEJMoa1703643

6. Witzel I, Loibl S, von Minckwitz G, et al. Monitoring serum HER2 levels during neoadjuvant trastuzumab treatment within the GeparQuattro trial. Breast Cancer Res Treat. 2010;123(2):437-445. doi:10.1007/s10549-010-1030-9

7. Lin L, Sirohi D, Coleman JF, Gulbahce HE. American society of clinical oncology/college of American pathologists 2018 focused update of breast cancer HER2 FISH testing guidelines results from a national reference laboratory. Am J Clin Pathol. 2019;152 (4):479-485. doi:10.1093/ajcp/aqz061

8. Tsé C, Gauchez A-S, Jacot W, Lamy P-J. HER2 shedding and serum HER2 extracellular domain: biology and clinical utility in breast cancer. Cancer Treat Rev. 2012;38(2):133-142. doi:10.1016/j.ctrv.2011.03.008

9. Gotzsche PC, Jorgensen KJ. Screening for breast cancer with mammography. Cochrane Database Syst Rev. 2013;6:CD001877.

10. Lam L, McAndrew N, Yee M, Fu T, Tchou JC, Zhang H. Challenges in the clinical utility of the serum test for HER2 ECD. Biochim Biophys Acta. 2012;1826(1):199-208. doi:10.1016/j.bbcan.2012.03.012

11. Shamsipur M, Emami M, Farzin L, Saber R. A sandwich-type electrochemical immunosensor based on in situ silver deposition for determination of serum level of HER2 in breast cancer patients. Biosens Bioelectron. 2018;103:54-61. doi:10.1016/j.bios.2017.12. 022
12. Harris LN, Liotcheva V, Broadwater G, et al. Comparison of methods of measuring HER-2 in metastatic breast cancer patients treated with high-dose chemotherapy. J Clin Oncol. 2001;19(6):1698-1706. doi:10.1200/JCO.2001.19.6.1698

13. Mansour OA, Zekri AR, Harvey J, Teramoto Y, El-Ahmady O. Tissue and serum c-erbB-2 and tissue EGFR in breast carcinoma: three years follow-up. Anticancer Res. 1997;17(4B):3101-3106.

14. Edge SB, Compton CC. The American joint committee on cancer: the 7 th edition of the AJCC cancer staging manual and the future of TNM. Ann Surg Oncol. 2010;17(6):1471-1474. doi:10.1245/s10434010-0985-4

15. Qian XL, Wen HY, Yang YL, et al. Assessment of dual-probe Her-2 fluorescent in situ hybridization in breast cancer by the 2013 ASCO/ CAP guidelines produces more equivocal results than that by the 2007 ASCO/CAP guidelines. Breast Cancer Res Treat. 2016;159 (1):31-39. doi:10.1007/s10549-016-3917-6

16. Iqbal N, Iqbal N. Human epidermal growth factor receptor 2 (HER2) in cancers: overexpression and therapeutic implications. Mol Biol Int. 2014;2014:852748. doi:10.1155/2014/852748

17. Wolff AC, Hammond MEH, Allison KH, et al. Human epidermal growth factor receptor 2 testing in breast cancer: American society of clinical oncology/college of American pathologists clinical practice guideline focused update. J Clin Oncol. 2018;36(20):2105-2122. doi:10.1200/JCO.2018.77.8738

18. Rubin I, Yarden Y. The basic biology of HER2. Ann Oncol. 2001;12 (Suppl 1):S3-S8. doi:10.1093/annonc/12.suppl_1.S3

19. Slamon DJ, Clark GM, Wong SG, Levin WJ, Ullrich A, McGuire WL. Human breast cancer: correlation of relapse and survival with amplification of the HER-2/neu oncogene. Science. 1987;235(4785):177-182. doi:10.1126/science.3798106

20. Loibl S, Gianni L. HER2-positive breast cancer. Lancet. 2017;389 (10087):2415-2429. doi:10.1016/S0140-6736(16)32417-5

21. Andersen TI, Paus E, Nesland JM, McKenzie SJ, Borresen AL. Detection of c-erbB-2 related protein in sera from breast cancer patients. Relationship to ERBB2 gene amplification and c-erbB-2 protein overexpression in tumour. Acta Oncol. 1995;34(4):499-504. doi: $10.3109 / 02841869509094014$

22. Krainer M, Brodowicz T, Zeillinger R, et al. Tissue expression and serum levels of HER-2/neu in patients with breast cancer. Oncology. 1997;54(6):475-481. doi:10.1159/000227606

23. Ludovini V, Gori S, Colozza M, et al. Evaluation of serum HER2 extracellular domain in early breast cancer patients: correlation with clinicopathological parameters and survival. Ann Oncol. 2008;19 (5):883-890. doi:10.1093/annonc/mdm585

24. Cheung KL, Pinder SE, Paish C, et al. The role of blood tumor marker measurement (using a biochemical index score and c-erbB2) in directing chemotherapy in metastatic breast cancer. Int $J$ Biol Markers. 2000;15(3):203-209. doi:10.1177/172460080001500310

25. Redig AJ, McAllister S. Breast cancer as a systemic disease: a view of metastasis. J Intern med. 2013;274(2):113-126.

26. Sundquist M, Brudin L, Tejler GJTB. Improved survival in metastatic breast cancer 1985-2016. Breast. 2017;31:46-50.

27. Matsumoto A, Jinno H, Murata T, et al. Prognostic implications of receptor discordance between primary and recurrent breast cancer. Int J Clin oncol. 2015;20(4):701-708.

28. Khalkhali I, Mena I, Diggles L. Review of imaging techniques for the diagnosis of breast cancer: a new role of prone scintimammography using technetium-99m sestamibi. Eur J Nucl Med. 1994;21(4):35 7-362. doi:10.1007/BF00947973 


\section{Publish your work in this journal}

Cancer Management and Research is an international, peer-reviewed open access journal focusing on cancer research and the optimal use of preventative and integrated treatment interventions to achieve improved outcomes, enhanced survival and quality of life for the cancer patient
The manuscript management system is completely online and includes a very quick and fair peer-review system, which is all easy to use. Visit http://www.dovepress.com/testimonials.php to read real quotes from published authors.

Submit your manuscript here: https://www.dovepress.com/cancer-management-and-research-journal 